\title{
Evaluation of Tablets Containing a Probiotic Strain for an Oral Administration
}

\author{
María Teresa Sánchez, María AdolfinaRuiz and María Encarnación Morales \\ Department of Pharmacy and Pharmaceutical Technology, Faculty of Pharmacy, University of Granada, Granada 18071, Spain
}

\begin{abstract}
The scientific concept of probiotics has been widely accepted throughout the last decades; consequently, its industrial production and commercialization have been increased. This is only the beginning since a recent global probiotic market analysis estimated an annual growth, boosted mainly by a rising request from the Asian and European consumer in the next 5 years. So the pharmaceutical industry needs to develop new dosage forms containing probiotic microorganisms in order to offer consumers a variety of products. Different kinds of matrix tablets with Lactobacillus coryniformis CECT 5711 were designed to protect this strain from the technological process and harsh gastrointestinal conditions up until their arrival in the gut, as well as environmental conditions during their storage. With this aim, various retarding polymers were combined so as to get controlled release tablets. All formulations were evaluated in terms of technological processability, bacterial viability and stability. Finally, an optimal formulation with Methocel ${ }^{\mathbb{R}}$ K-15 M EP, Eudragit L-100 and alginate sodium, which contain Lactobacillus coryniformis CECT 5711, was selected due to the fact that it assured an excellent survival of the microorganisms after their exposition to all conditions mentioned above, besides it will be able to improve human's health.
\end{abstract}

Key words: Lactobacillus coryniformis, matrix tablets, retarding polymers, health.

\section{Introduction}

The concept of probiotic was probably firstly introduced by the Russian Nobel laureate Elie Metchnikoff in 1907 (The Prolongation of Life: Optimistic Studies), he supported the idea that this kind of microbes were beneficial to human gastrointestinal tract [1]. The WHO (World Health Organization) and the Food and Agriculture Organization of the United Nations have defined probiotics as "live microorganism, which, when administered in adequate amounts, confer a health benefit on the host". This adequate amount varies from country to country; however, generally a probiotic product should contain more than $10^{6} \sim 10^{8} \mathrm{CFU} / \mathrm{g}$ or $>10^{8} \sim 10^{10} \mathrm{CFU}$ (colony forming units)/dosage of viable cells [2]. Commercially, the most commonly used bacterial probiotics are Lactobacillus, Bifidobacteria, non-pathogenic $\quad$. coli Nissle 1917 and Saccharomyces boulardii. Increasing market interest in

Corresponding author: María Encarnación Morales, Ph.D., research fields: Pharmaceutical Technology. promoting health in a natural way has intensified research in this area. Today, the practical use of food and supplements, including probiotics, is driven by "soft" health effects and promotion of well-being rather than the treatment of disease symptoms [3]. Nevertheless, there is enough evidence about the success of probiotics in different diseases like infant diarrhea $[4,5]$, antibiotic-associated-diarrhea [6], traveler's diarrhea [7], ulcerative colitis [8-10] and Crohn disease [11], lactose intolerance [12], Helicobacter pylori eradication [13-15], pulmonary infections [16], low cholesterol level [17-19], antiobesity [20] and diabetes [21], allergy [22, 23], atopic eczema and skin diseases [24], cancer [25, 26] and urogenital infection [27]. Clinical trials have used various formulations and strains and the overall conclusion is that strain specificity and disease setting is important, whilst dosage and route, duration and frequency of administration must also be considered carefully [28].

Lactobacillus coryniformis CECT 5711 was isolated 
from an artisanal cheese elaborated from goat's milk by Biosearch Life; it was selected because of its broad antimicrobial activity within other probiotics properties like a high cellular adhesion and a 50\% of survival in stomach [29]. Furthermore, this strain is well tolerated [30] and exerts a beneficial effect in the bowel function of healthy adult [31]. Studies are in progress to elucidate the effects of this strain on immunological parameters of healthy adult host [31, 32].

The main problem associated with the administration of probiotic microorganisms is to maintain the survival of them along the gastrointestinal tract and storage conditions; therefore, there is a need for formulations which could protect the bacteria from the stomach acid and bile effects. It seems hard to judge whether probiotic food or supplements act more efficiently in exerting the claimed health effects. To our knowledge, only one study has compared the survivability of probiotic bacteria in food versus supplements. The results showed that the capsules used as supplement did not protect lactobacilli strain until the end of the gastrointestinal tract but the health effectiveness was not investigated and compared. Different forms of probiotic supplements are available in the market including pills, capsules, tablets, gelcaps, liquids and powders. In the pharmaceutical field, acid labile drugs are formulated mainly in tablets, which are able to ensure a higher protection and deliver the active substances into the intestinal tract. In addition, tablets have advantages over other dosage forms; these are ease of administration, accurate dosage, good patient acceptance and suitability for large-scale production [33, 34]. Based on this knowledge, we investigated whether it is possible to design a probiotic tablet supplement, which protects them from degradation at low $\mathrm{pH}$ and lets the delivery of the viable probiotics into the colon carrying out the beneficial effects. In this sense, we employ different polymers according to our objective; these polymers are for example hydroxypropyl methylcellulose (Methocel ${ }^{\circledR}$ K-15 M
EP) [35-41] and sodium alginate [42, 43], which form hydrophilic matrix tablets in contact with aqueous media. Bacteria released from this kind of tablets are controlled by the formation of a hydrated viscous layer around the tablet, after ingestion of the dosage form. The surface acts as a release barrier by opposing penetration of water into the tablet and the dissolution of the matrix. The release of the microorganisms could be by diffusion through the gel layer or by erosion [44-48], in this case, the release of the probiotic bacteria is by diffusion. The cellulose acetate phthalate provides lipophilic matrix tablets with an erosion process, which allows the probiotic release. Other polymers are Eudragit $^{\circledR}$ L-100, a metacrylic acid-ethhylacrylate copolymer [49, 50] and ethylcellulose, which is water-insoluble, both form inert matrix and its combination were investigated to overcome the problems of colonic delivery systems, such as a too short gastric resistance and premature release [50].

In the present study, we intend to develop different matrix tablets with Lactobacillus coryniformis CECT 5711, a probiotic strain, which can achieve an optimal survival of bacteria after technological process, gastrointestinal tract until colon and storage conditions with the possibility of being marketed. Lastly, the current probiotic interest from consumers, scientists, and healthcare workers will only increase as more and better information is becoming available [51].

\section{Materials and Methods}

\subsection{Materials}

Lyophilized batches of the lactic acid bacteria strain Lactobacillus coryniformis CECT 5711 were supplied by Biosearch Life S.A (Spain). Sodium alginate, talcum and magnesium stearate were purchased from Guinama (Spain), Methocel $^{\circledR}$ K-15 M EP (HPMC (hydroxypropylmethylcellulose)) from Palex Laboratories S.A (Spain), Eudragit ${ }^{\circledR}$ L-100 from Degussa (Germany), EC (ethyl cellulose) from Dow Chemical Company (USA), cellulose acetate phthalate 
from Sigma- Aldrich Company (USA).

\subsection{Methods}

\subsubsection{Tablets Preparation}

Tablet processing took place by direct compression using a single punch manual tablet press (SPECAC SC-15011, Spain) connected to a pressure gauge. An exact amount of powder mixture containing Lactobacillus coryniformis CECT 5711 and different polymers in each case was poured into a $10 \mathrm{~mm}$ diameter die under a certain force ranging from 5 to $25 \mathrm{kN}$ and several compression times. Tablets with plane surface were formed. The polymers were used in order to achieve a controlled release. Besides of polymers, tablets also contain a suitable amount of magnesium stearate as lubricant and talcum as antiadherant $(0.1 \%$ and $0.9 \%, w / w$, respectively). Tablets formulations designed in this study are summarized in Table 1.

2.2.2 Technological Evaluation

Once obtained probiotic tablets, they must be evaluated according to United States Pharmacopeia (USP 29) and Real Farmacopea Española (RFE, $3^{\mathrm{a}}$ Ed) methods for modified release tablets. They were evaluated in order to know their disintegration, tensile strength, friability and mass uniformity [52, 53].

Disintegration of tablets was examined by means of a disintegration apparatus (Erweka, Germany) and they were placed separately in the test chamber and then immersed in HCL 37\% for $1 \mathrm{~h}$ and then in phosphate buffer solution PBS pH 6.8 for $24 \mathrm{~h}$ at $37^{\circ} \mathrm{C}$; the disintegration test ends when in each test chamber there is a soft residue of the tablets and it is completely impregnated and never is a non impregnated core [52-54].

Tablets' mechanical strength was determined by using an Erweka TBH 20 (Germany) tester and the tensile strength $(\sigma)$ was calculated by the following equation, where $P$ is the measured crushing force $(N)$, $D$ is diameter and $t$ is the thickness of the tablets [55]:

$$
\sigma=2 P / \pi D t
$$

Table 1 Probiotic tablets formulations.

\begin{tabular}{|c|c|c|c|c|c|c|}
\hline Formulation & $\begin{array}{l}\text { Probiotic bacteria } \\
\text { (mg) }\end{array}$ & $\begin{array}{l}\text { Sodiumalginate } \\
\text { (mg) }\end{array}$ & $\begin{array}{l}\text { Methocel }^{\circledR} \\
\text { K-15 M EP (mg) }\end{array}$ & $\begin{array}{l}\text { Cellulose acetate } \\
\text { phthalate (mg) }\end{array}$ & $\begin{array}{l}\text { Eudragit } \\
\text { L-100 (mg) }\end{array}$ & $\begin{array}{l}\text { EC (ethylcellulose) } \\
\text { (mg) }\end{array}$ \\
\hline 1 & 100 & 100 & 100 & - & - & - \\
\hline 2 & 100 & 100 & 75 & 25 & - & - \\
\hline 3 & 100 & 100 & 50 & 50 & - & - \\
\hline 4 & 100 & 100 & 25 & 75 & - & - \\
\hline 5 & 100 & 100 & - & 100 & - & - \\
\hline 6 & 100 & 75 & 100 & 25 & - & - \\
\hline 7 & 100 & - & 100 & 100 & - & - \\
\hline 8 & 100 & 100 & 75 & - & 25 & - \\
\hline 9 & 100 & 100 & 50 & - & 50 & - \\
\hline 10 & 100 & 100 & 25 & - & 75 & - \\
\hline 11 & 100 & 100 & - & - & 100 & - \\
\hline 12 & 100 & 75 & 100 & - & 25 & - \\
\hline 13 & 100 & 50 & 100 & - & 50 & - \\
\hline 14 & 100 & 25 & 100 & - & 75 & - \\
\hline 15 & 100 & - & 100 & - & 100 & - \\
\hline 16 & 100 & - & 100 & - & 95 & 5 \\
\hline 17 & 100 & - & 50 & - & 142.5 & 7.5 \\
\hline 18 & 100 & - & 25 & - & 166.25 & 8.75 \\
\hline 19 & 100 & - & 100 & - & 90 & 10 \\
\hline 20 & 100 & - & 50 & - & 135 & 15 \\
\hline 21 & 100 & - & 25 & - & 157.5 & 17.5 \\
\hline
\end{tabular}

“-”: Formulation does not contain the polymer. 
Tablets' friability was measured by using a friabilator (Erweka GmbH, Germany) and mass uniformity test was realized with a precision balance (A\&D Europe GmbH, Germany).

\subsubsection{In Vitro Determination of Cell Release}

Dissolution test was arranged according to our type of tablets with the aim of evaluating the release speed of probiotic microorganism and their gastric juice resistant by using the USP paddle method, with a paddle speed of 100 revolutions per minute (rpm) at $37{ }^{\circ} \mathrm{C}$. Tablets were transferred into $600 \mathrm{~mL}$ of $0.04 \mathrm{~N}$ HCL acid (pH 1.7) during $2 \mathrm{~h}$ and then in PBS pH 6.8 for $4 \mathrm{~h}$. At the end of the assay, the medium was removed and the viable cells inside tablets were determined. The test was realized in triplicate.

2.2.4 Viability of Cells Inside the Tablets: Microbiological Cultures

Each tablet was broken and dispersed in $50 \mathrm{~mL}$ of PBS pH 7. Tablets should be shaken during $1 \mathrm{~h}$ in an orbital shaker. After this time, a serial dilution of the suspension was made until a suitable cell density. Cell suspension was then spread onto MRS agar plates. These plates were incubated at $37{ }^{\circ} \mathrm{C}$ for $48 \mathrm{~h}$. This procedure was carried out in duplicates. Colonies of bacteria were counted and converted to $\log \mathrm{CFU}$ (colony forming units). The survival of probiotic cells was studied.

\subsubsection{Stability of Probiotic Tablets}

So as to perform stability testing, tablets were kept in hermetic containers at $4{ }^{\circ} \mathrm{C}, 25{ }^{\circ} \mathrm{C}$ and $\mathrm{RT}$ (room temperature) for one year. The stability of bacterial cells in these tablets throughout the storage period was investigated. The method used to determine cell viability was the plating procedure described above.

\section{Results and Discussion}

\subsection{Bacterial Viability after Tableting}

With the aim of selecting the best formulations, the effects of compression force and polymers on probiotic viability, as well as the stability of probiotic tablets during the storage at different temperatures, were studied.

A screening of compression force was carried out with several tablets that contained probiotic cells (Table 2). The assay was carried out in triplicate with all formulations. On account of the results that we had obtained (Table 2), $15 \mathrm{kN}$ of compression force was selected as the optimal since all tablets have similar technological properties and adequate viability. We prepared our tablets with $0.1 \mathrm{~g}$ of this lyophilized, so the theoretical viability inside the tablets should be $1 \times$ $10^{10} \mathrm{CFU} /$ tablet. As we can see in Table 3 , the viability inside tablets after applying $15 \mathrm{kN}$ of compression force ranged from $2 \times 10^{9}$ to $6 \times 10^{9} \mathrm{CFU}$. The lethal effect of compression may be attributable to shearing forces caused by interparticules movement and pore size reduction within the matrix, leading to mechanical damage and death of the cells [56]. Some authors recommend a probiotic dosage of 5 billion CFU for at least 5 days in order to improve huma's health [57]. Furthermore, Lara-Villoslada et al. [30] reported that a

Table 2 Tablets compression force with probiotic bacteria $(n=3)$. Results obtained after applying different compression forces $(\mathrm{kN})$ during $30 \mathrm{~s}$ or $60 \mathrm{~s}$ to a powder mixture which contained probiotic bacteria.

\begin{tabular}{lll}
\hline \multicolumn{2}{c}{ Tablet processing condition } & Results \\
\hline Compression force $(\mathrm{kN})$ & Time $(\mathrm{s})$ & The compression force isn't enough: \\
5 & 30 & High friability and low tensile strength were observed \\
\hline \multirow{2}{*}{15} & 60 & Optimal friability and tensile strength \\
\hline \multirow{2}{*}{20} & 30 & High tensile strength, unbreakable tablets \\
\cline { 2 - 3 } 25 & 60 & \\
\hline
\end{tabular}


dosage of $2 \times 10^{9} \mathrm{CFU} / \mathrm{day}$ of Lactobacillus coryniformis CECT 5711 enhanced intestinal function and caused an increment in several immunological parameters. So, despite the loss of 1 log CFU during compression, this force of $15 \mathrm{kN}$ assured an adequate probiotic survival and its beneficial effects, overcoming high compression forces issues.

\subsection{Probiotic Bacteria Survival inside Tablets in} Gastric Juice

In order to provide beneficial health effects for the host, probiotic bacteria must survive through the gastrointestinal tract, tolerating acid and then adhere to and colonize the intestinal epithelium [58]. Firstly, probiotic bacteria resistance in acid was studied with the aim of selecting those formulations with an optimal viability after their immersion for $2 \mathrm{~h}$ in acid $(\mathrm{HCl} 0.04 \mathrm{~N})$. Table 3 shows cells viability of each formulation just after tableting and after their exposure to gastric conditions.
If we compare all formulations, viability after their exposure to gastric conditions was reduced by $1 \log \mathrm{CFU}$ in most of them. However, Formulations 4 and 5 were more affected by acid and their decrease in viability was $2 \log C F U$. According to Stadler and Viernstein [52], the decrease of $1 \log$ unit after 2 h of contact with acidic medium was a good achievement. As it is shown in Table 3, Formulations 10, 12 and 14 had the best acid resistance results. If we consider the combination of Eudragit L-100 and EC, Formulations 16 and 17 had also a good resistance. However, between both formulations we selected only Formulation 17 for futher study because of its higher amount of Eudragit/EC (2.5\%) according to Rujivipat and Bodmeier [50], who claims that the addition of ethylcellulose to the enteric Eudragit $\mathrm{L}$ decreases the release of water-soluble drugs at low $\mathrm{pH}$; surprisingly, the addition of only $2.5 \%$ ethylcellulose prolonged the gastric resistance beyond $18 \mathrm{~h}$. Increasing the ethylcellulose amount decreased the weight increase

Table 3 Probiotic viability inside tablets after immersing $2 \mathrm{~h}$ in $\mathrm{HCl} 0.04 \mathrm{~N}$ (pH 1.8).

\begin{tabular}{lll}
\hline Formulation & $\begin{array}{l}\text { Initial viability } \\
\text { (CFU/tablet) after tableting* }\end{array}$ & $\begin{array}{l}\text { Viability after } 2 \text { h in acid* } \\
\text { (CFU/tablet) }\end{array}$ \\
\hline 1 & $5 \times 10^{9} \pm 3.32 \times 10^{8}$ & $1 \times 10^{8} \pm 0.00$ \\
2 & $5 \times 10^{9} \pm 2.50 \times 10^{8}$ & $6 \times 10^{8} \pm 4.62 \times 10^{7}$ \\
3 & $3 \times 10^{9} \pm 4.27 \times 10^{8}$ & $1 \times 10^{8} \pm 3.95 \times 10^{6}$ \\
4 & $7 \times 10^{9} \pm 3.56 \times 10^{8}$ & $2 \times 10^{7} \pm 1.26 \times 10^{6}$ \\
5 & $4 \times 10^{9} \pm 8.16 \times 10^{7}$ & $4 \times 10^{7} \pm 5.00 \times 10^{6}$ \\
6 & $5 \times 10^{9} \pm 3.70 \times 10^{8}$ & $3 \times 10^{8} \pm 1.41 \times 10^{6}$ \\
7 & $5 \times 10^{9} \pm 0.00$ & $1 \times 10^{8} \pm 0.00$ \\
8 & $5 \times 10^{9} \pm 0.00$ & $3 \times 10^{8} \pm 1.29 \times 10^{7}$ \\
9 & $5 \times 10^{9} \pm 1.25 \times 10^{8}$ & $6 \times 10^{7} \pm 4.62 \times 10^{6}$ \\
10 & $8 \times 10^{9} \pm 2.63 \times 10^{8}$ & $5 \times 10^{8} \pm 1.50 \times 10^{7}$ \\
11 & $5 \times 10^{9} \pm 3.70 \times 10^{8}$ & $2 \times 10^{8} \pm 1.73 \times 10^{7}$ \\
12 & $5 \times 10^{9} \pm 3.32 \times 10^{8}$ & $5 \times 10^{8} \pm 1.00 \times 10^{7}$ \\
13 & $3 \times 10^{9} \pm 1.41 \times 10^{8}$ & $2 \times 10^{8} \pm 2.06 \times 10^{7}$ \\
14 & $5 \times 10^{9} \pm 1.50 \times 10^{8}$ & $5 \times 10^{8} \pm 1.41 \times 10^{6}$ \\
15 & $2 \times 10^{9} \pm 0.00$ & $2 \times 10^{8} \pm 5.00 \times 10^{7}$ \\
16 & $4 \times 10^{9} \pm 1.73 \times 10^{7}$ & $5 \times 10^{8} \pm 1.50 \times 10^{7}$ \\
17 & $5 \times 10^{9} \pm 0.00$ & $5 \times 10^{8} \pm 4.75 \times 10^{6}$ \\
18 & $3 \times 10^{9} \pm 9.57 \times 10^{8}$ & $1 \times 10^{8} \pm 5.00 \times 10^{7}$ \\
19 & $3 \times 10^{9} \pm 1.40 \times 10^{9}$ & $1.5 \times 10^{8} \pm 5.77 \times 10^{7}$ \\
20 & $5 \times 10^{9} \pm 0.00$ & $1 \times 10^{8} \pm 4.59 \times 10^{7}$ \\
21 & $7.50 \times 10^{9} \pm 4.79 \times 10^{9}$ & $1 \times 10^{8} \pm 3.96 \times 10^{7}$ \\
\hline
\end{tabular}

*Values are mean $(n=3) \pm \mathrm{SD}$ (standard deviation). 
(swelling) in acid and decreased the weight loss and erosion in lag conditions, thus the acid uptakes were $42 \%$ and 3\% for (Eudragit L):ethylcellulose blends of 95:5 and 90:10, respectively.

All of these formulations kept a viability of $5 \times 10^{8}$ CFU/tablet after the assay, which is considered as therapeutic dosage [2]. Probably, tablets had improved the stability of the remaining bacteria in comparison with the lyophilized bacteria due to the reduction of the exchange surface with the environment after compression [59].

\subsection{Technological Evaluation}

Each of the four formulations previously selected, were subjected to technological tests (mass uniformity, friability and tensile strength). Although disintegration test is not mandatory for this matrix tablets, it was carried out with the aim of studying the changes that tablets suffers through the gastrointestinal tract. After the disintegration assay, it was demonstrated the complete disintegration and the non-presence of tablets residues in the organism within $24 \mathrm{~h}$ (Figs. 1-4).

Mass uniformity was calculated as the mass average of 20 samples, whilst friability and tensile strength was calculated with 10 samples for each formulation. The results obtained (Table 4) showed that all formulations have an adequate hardness to an easy-manipulation (friability $<1 \%$ ). Furthermore, tensile strength is

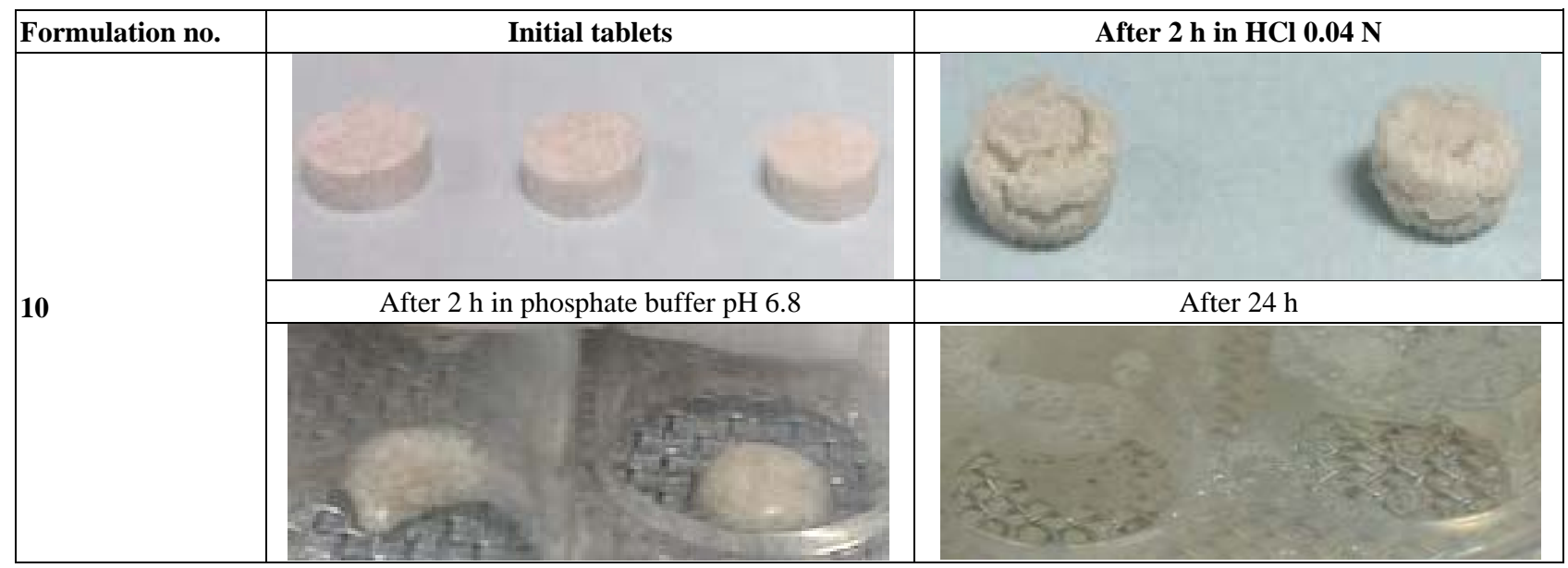

Fig. 1 Formulation 10 disintegration test $(24 \mathrm{~h})(n=6)$. Tablets behavior and appearance after been immersed $2 \mathrm{~h}$ in $\mathrm{HCl} 0.04$ $\mathrm{N}$ and Phosphate buffer pH 6.8 until $24 \mathrm{~h}$.

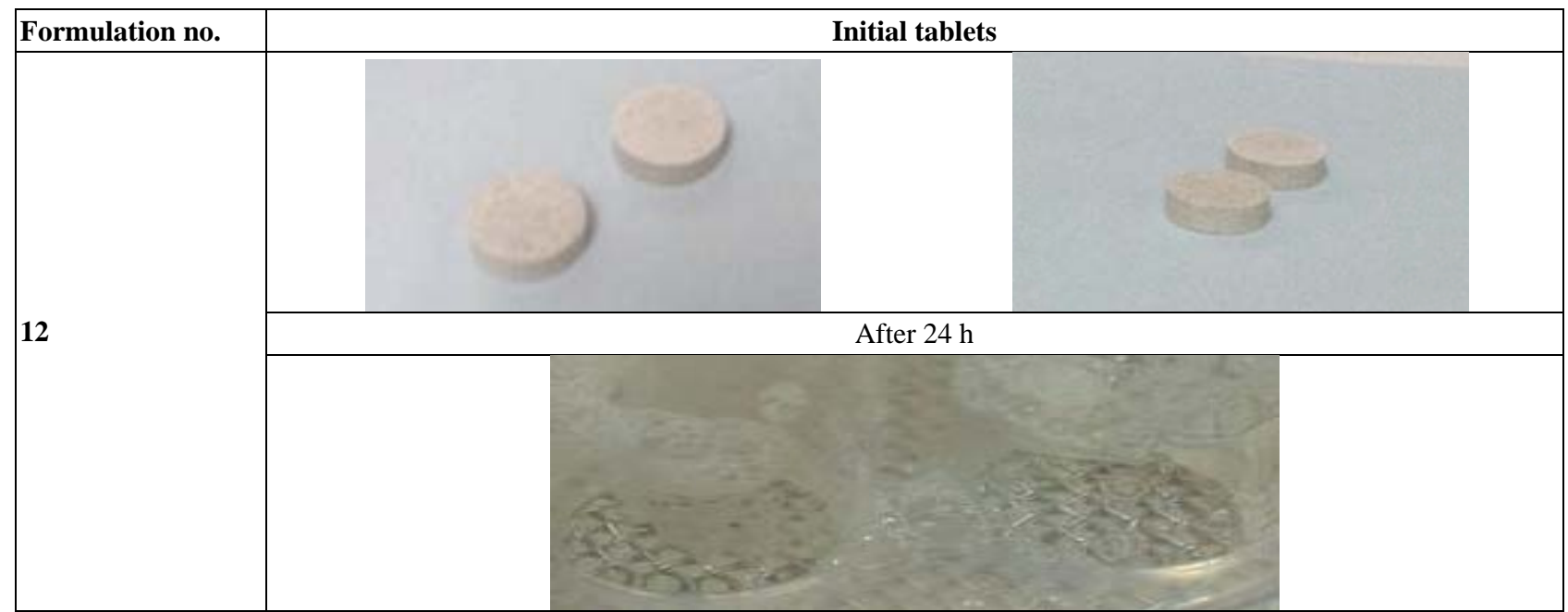

Fig. 2 Formulation 12 disintegration test $(24 \mathrm{~h})(n=6)$. Tablets behavior and appearance after been immersed $2 \mathrm{~h}$ in $\mathrm{HCl} 0.04$ $\mathrm{N}$ and Phosphate buffer pH 6.8 until 24 h. 


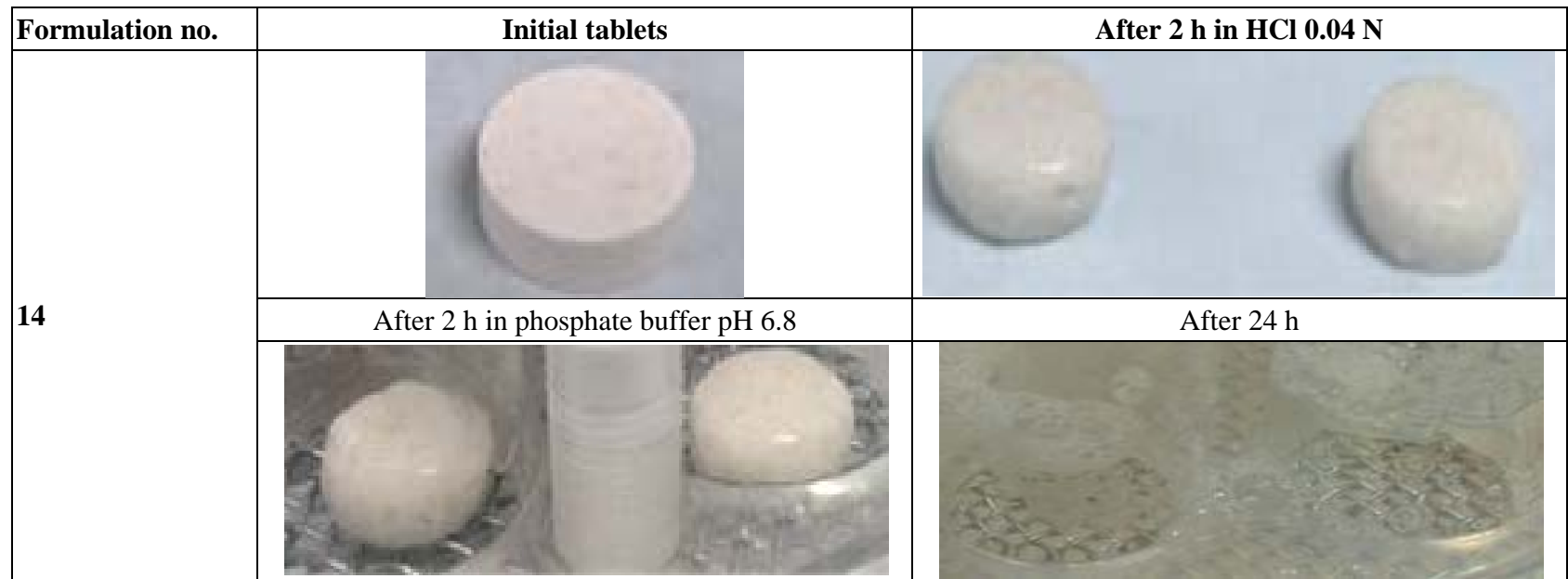

Fig. 3 Formulation 14 disintegration test $(24 \mathrm{~h})(n=6)$. Tablets behavior and appearance after been immersed $2 \mathrm{~h}$ in $\mathrm{HCl}$ 0.04 N and Phosphate buffer pH 6.8 until 24 h.

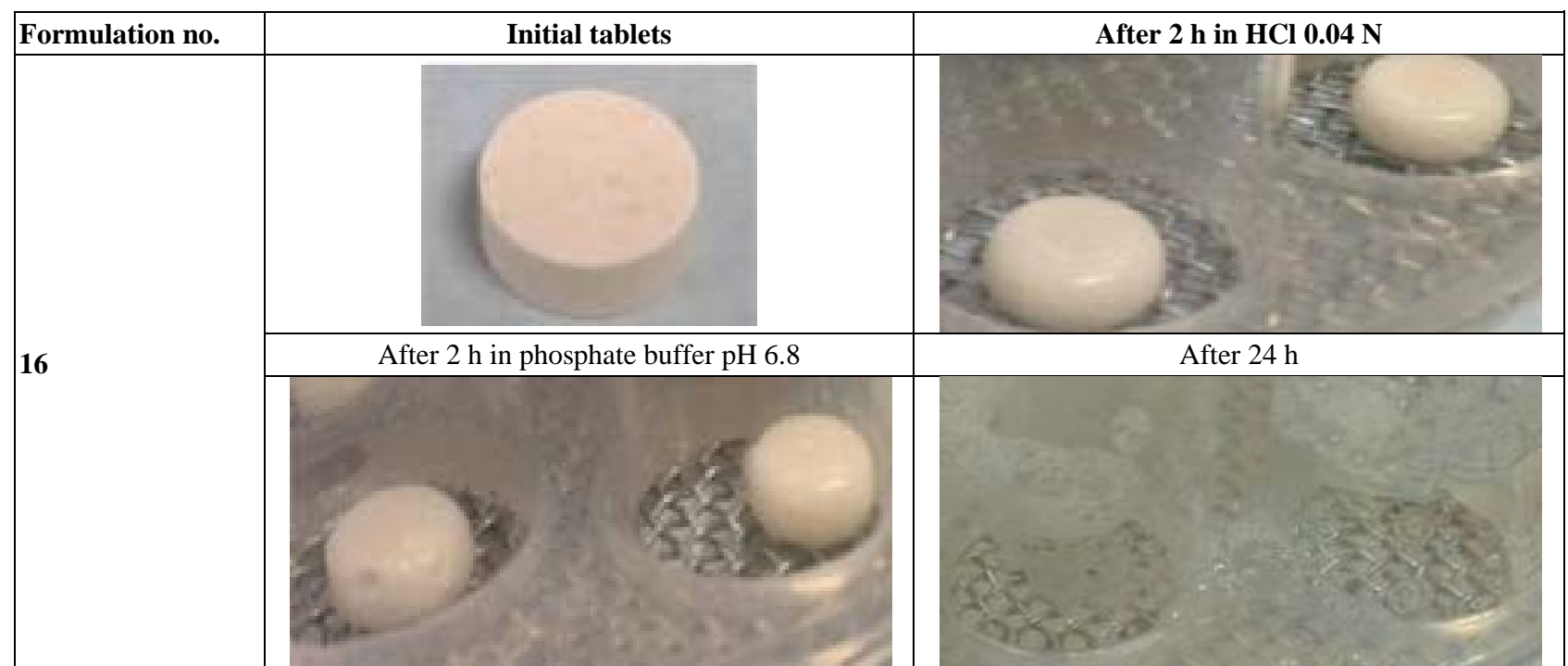

Fig. 4 Formulation 1 disintegration test $(24 \mathrm{~h})(n=6)$. Tablets behavior and appearance after been immersed $2 \mathrm{~h}$ in $\mathrm{HCl} 0.04$ $\mathrm{N}$ and Phosphate buffer pH 6.8 until $24 \mathrm{~h}$.

Table 4 Tablets technological tests. Formulations 10, 12, 14 and 16 were submitted to mass uniformity, friability and tensile strength test.

\begin{tabular}{llll}
\hline Formulation & Mass uniformity $(\mathrm{g})^{*}$ & Friability* & Tensile strength $\left(\mathrm{N} / \mathrm{mm}^{2}\right)^{* *}$ \\
\hline 10 & $0.3189 \pm 0.016$ & $<1 \%$ & $5.87 \pm 0.30$ \\
12 & $0.3165 \pm 0.016$ & $<1 \%$ & $4.65 \pm 0.62$ \\
14 & $0.3190 \pm 0.016$ & $<1 \%$ & $6.34 \pm 0.42$ \\
16 & $0.3165 \pm 0.016$ & $<1 \%$ & $5.69 \pm 0.58$ \\
\hline
\end{tabular}

*Values are mean $(n=20) \pm$ SD (standard deviation);

**Values are mean $(n=10) \pm \operatorname{SD}$ (standard deviation).

between $4.65 \pm 0.62 \mathrm{~N} / \mathrm{mm}^{2}$ and $6.34 \pm 0.42 \mathrm{~N} / \mathrm{mm}^{2}$, which is optimal according to Muller et al. [59] who consider that pharmaceutical tablets should have a tensile strength $\geq 1.5 \mathrm{~N} / \mathrm{mm}^{2}$, otherwise, it will be necessary for the addition of excipient to increase the cohesion.

\subsection{In Vitro Determination of Cells Release}

The low $\mathrm{pH}$ and pepsin can be considered as the main detrimental factors for probiotics viability in the 
stomach. The $\mathrm{pH}$ of the stomach generally ranges from 2.5 to 3.5 , but it can be as low as $\mathrm{pH} 1$ or $\mathrm{pH} 2$ at higher rates of gastric juice secretion or higher than $\mathrm{pH} 6$ after food digestion. Having passed through the stomach, ingested probiotics are faced with surviving in the small intestinal environment, where they are exposed to pancreatin, bile salts and an alkalinity between $\mathrm{pH} 7 \sim \mathrm{pH} 8$. Acid-bile tolerance and adhesive ability are essential considerations in evaluating the efficacy probiotic organisms [60]. It is important to consider the expression of the results and its interpretation; the best criterion is probably the concentration of probiotic at the target site [61, 62]. Table 5 and Fig. 5 show the results of the dissolution test and the survival of the probiotic bacteria along gastrointestinal tract.

First of all, tablets had to pass through stomach $(\mathrm{pH}$ $=1 \sim 2.5$ ) which takes $2 \mathrm{~h}$. After that, the viability of each formulation is $5 \times 10^{8} \mathrm{CFU} /$ tablets. Then tablets will reach the small intestine $(\mathrm{pH}=6.1 \sim 7.8)$ whose transit time until colon is about $3.2 \pm 1.6 \mathrm{~h}$, so we continued the assay simulating these conditions for $4 \mathrm{~h}$. After $2 \mathrm{~h}$ in small intestine, viability inside tablets has decreased in $1 \log \mathrm{CFU}\left(10^{7} \mathrm{CFU} /\right.$ tablet $) .4 \mathrm{~h}$ later, tablets would be in colon, which was the target. At this time, Formulations 10, 14 and 16 maintained the viability $\left(10^{7}\right.$ UFC/tablet $)$, however, viability of Formulation 12 decreased in $1 \log \left(10^{6} \mathrm{CFU} /\right.$ tablet $)$.

Table 5 Dissolution test $(6 \mathrm{~h})$. Formulations 10, 12, 14 and 16 were submitted to a cell release test along gastrointestinal transit according to USP method.

\begin{tabular}{lllll}
\hline Formulation & $\begin{array}{l}\text { Initial viability } \\
\text { (CFU/tablet) }\end{array}$ & $\begin{array}{l}\text { Viability after 2 } \mathrm{h} \text { in acid* } \\
\text { (CFU/tablet) }\end{array}$ & $\begin{array}{l}\text { Viability after 2 } \mathrm{h} \text { in } \\
\text { phosphate buffer** } \\
\text { (CFU/tablet) }\end{array}$ & $\begin{array}{l}\text { Viability after 4 h in } \\
\text { phosphate buffer** } \\
\text { (CFU/tablet) }\end{array}$ \\
\hline 10 & $8 \times 10^{9} \pm 2.63 \times 10^{8}$ & $5 \times 10^{8} \pm 1.50 \times 10^{7}$ & $3 \times 10^{7} \pm 0.00$ & $2 \times 10^{7} \pm 6.93 \times 10^{6}$ \\
12 & $5 \times 10^{9} \pm 3.32 \times 10^{8}$ & $5 \times 10^{8} \pm 1.00 \times 10^{7}$ & $4.75 \times 10^{7} \pm 2.89 \times 10^{6}$ & $3.38 \times 10^{6} \pm 7.22 \times 10^{5}$ \\
14 & $5 \times 10^{9} \pm 1.50 \times 10^{8}$ & $5 \times 10^{8} \pm 1.41 \times 10^{7}$ & $7 \times 10^{7} \pm 2.99 \times 10^{6}$ & $2 \times 10^{7} \pm 7.07 \times 10^{6}$ \\
16 & $4 \times 10^{9} \pm 1.73 \times 10^{8}$ & $5 \times 10^{8} \pm 1.50 \times 10^{7}$ & $5 \times 10^{7} \pm 2.52 \times 10^{6}$ & $1 \times 10^{7} \pm 0.00$ \\
\hline
\end{tabular}

*HCl 0.04 N, pH 1.8;

**Phosphate buffer $\mathrm{pH} 6.8$;

Values are mean $(n=3) \pm \mathrm{SD}$ (standard deviation).

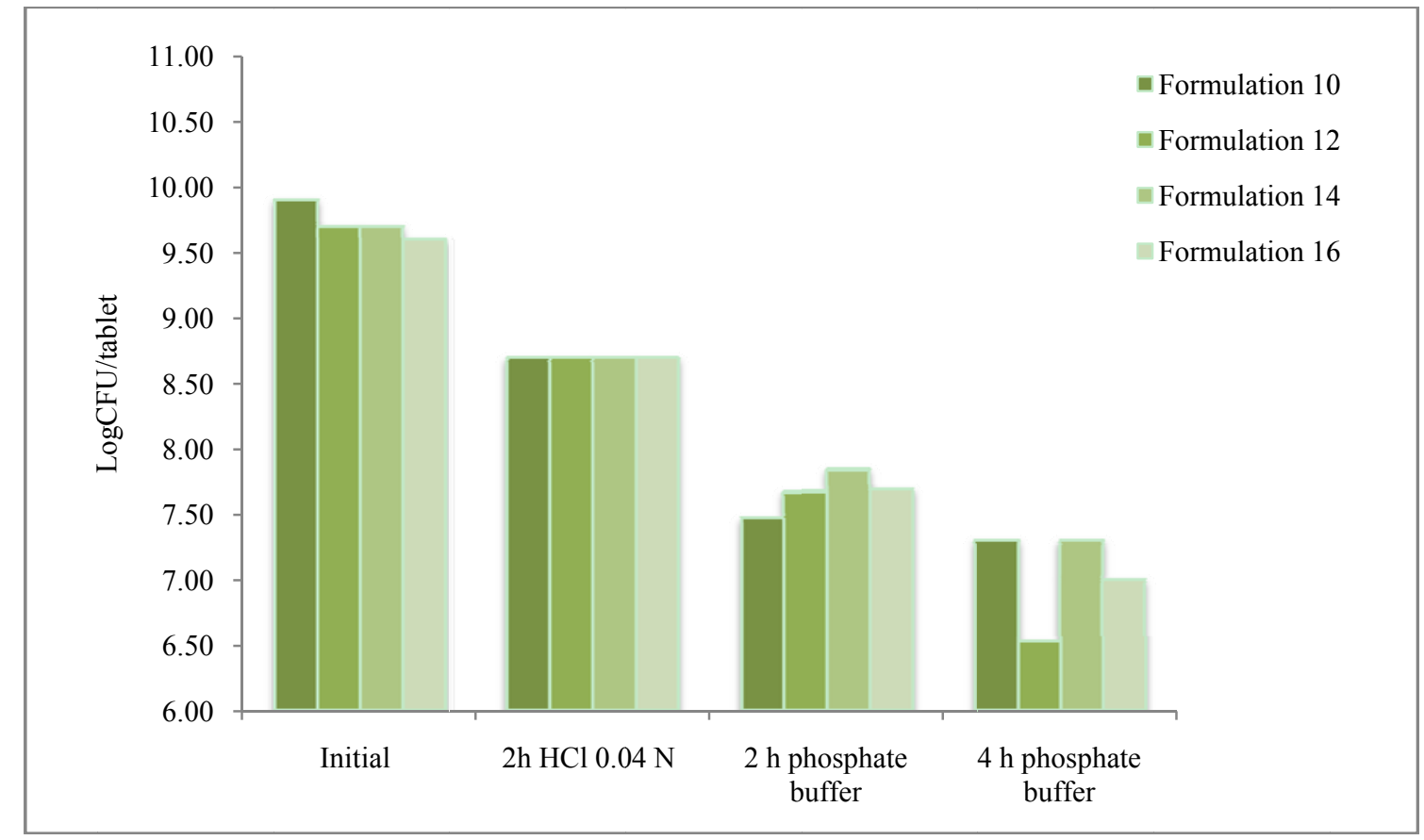

Fig. 5 Probiotic bacteria survival along gastrointestinal tract $(n=3)$. Viability of probiotic bacteria (logCFU/tablet) contained in Formulations 10, 12, 14 and 16 under simulated gastrointestinal conditions. 
In accordance with Marteau et al. [61], Formulations 10,14 and 16 with a viability of $10^{7} \mathrm{UFC} /$ tablet assured us an optimal number of $\mathrm{CFU}$ at the target site since the concentration of probiotics needed to obtain a clinical effect is often quoted as $\geq 10^{6} \mathrm{CFU} / \mathrm{g}$ from the small bowel to the colon. Furthermore, the strain Lactobacillus coryniformis CECT 5711 showed a survival rate in acid of approximately $50 \%$ [29], so not all the cells released in stomach are destroyed by acid and a half of them could have healthy effects there. Even so, there is evidence showing that the components of dead cells may be able to exert some anti-inflammatory responses [63]. Another important property of this strain is its strong adhesion to Caco-2 and HT-29 cells, which is higher than other strains like L.rhamnosus GG, L.jhonsonni La 1 and L. casei inmunitass [29].

\subsection{Stability of Probiotic Tablet}

The stability of one of the optimized formulations had been tested (Formulation 14) (Table 6 and Fig. 6). This formulation was selected in accordance with

Table 6 Formulation 14 storage stability and bacteria survival (CFU/tablet, CFU/g) during 365 days at different storage temperatures $\left(4^{\circ} \mathrm{C}, 25^{\circ} \mathrm{C}\right.$ and room temperature).

\begin{tabular}{llll}
\hline Time (days) & \multicolumn{3}{c}{ Storage temperature } \\
\cline { 2 - 4 } & $4^{\circ} \mathrm{C}(\mathrm{CFU} /$ tablet $)$ & $25^{\circ} \mathrm{C}(\mathrm{CFU} /$ tablet $)$ & RT (room temperature) $(\mathrm{CFU} /$ tablet $)$ \\
\hline 0 & $5.30 \times 10^{9} \pm 1.03 \times 10^{8}$ & $5.30 \times 10^{9} \pm 1.03 \times 10^{8}$ & $5.30 \times 10^{9} \pm 1.03 \times 10^{8}$ \\
15 & $2.50 \times 10^{9} \pm 7.06 \times 10^{8}$ & $1 \times 10^{9} \pm 1.15 \times 10^{8}$ & $2 \times 10^{9} \pm 2.77 \times 10^{8}$ \\
20 & $1.24 \times 10^{9} \pm 3.39 \times 10^{8}$ & $3 \times 10^{9} \pm 7.07 \times 10^{7}$ & $3 \times 10^{9} \pm 1.27 \times 10^{7}$ \\
30 & $2.35 \times 10^{9} \pm 4.95 \times 10^{8}$ & $4 \times 10^{9} \pm 1.41 \times 10^{8}$ & $3 \times 10^{9} \pm 2.97 \times 10^{8}$ \\
60 & $3.97 \times 10^{9} \pm 9.97 \times 10^{8}$ & $3 \times 10^{9} \pm 1.00 \times 10^{8}$ & $5 \times 10^{9} \pm 1.43 \times 10^{8}$ \\
90 & $5 \times 10^{9} \pm 2.18 \times 10^{8}$ & $5.35 \times 10^{9} \pm 3.32 \times 10^{8}$ & $5 \times 10^{9} \pm 3.75 \times 10^{7}$ \\
365 & $5 \times 10^{9} \pm 4.04 \times 10^{8}$ & $3.50 \times 10^{9} \pm 4.04 \times 10^{7}$ & $5 \times 10^{9} \pm 4.04 \times 10^{8}$
\end{tabular}

Values are mean $(n=3) \pm \mathrm{SD}$ (standard deviation).

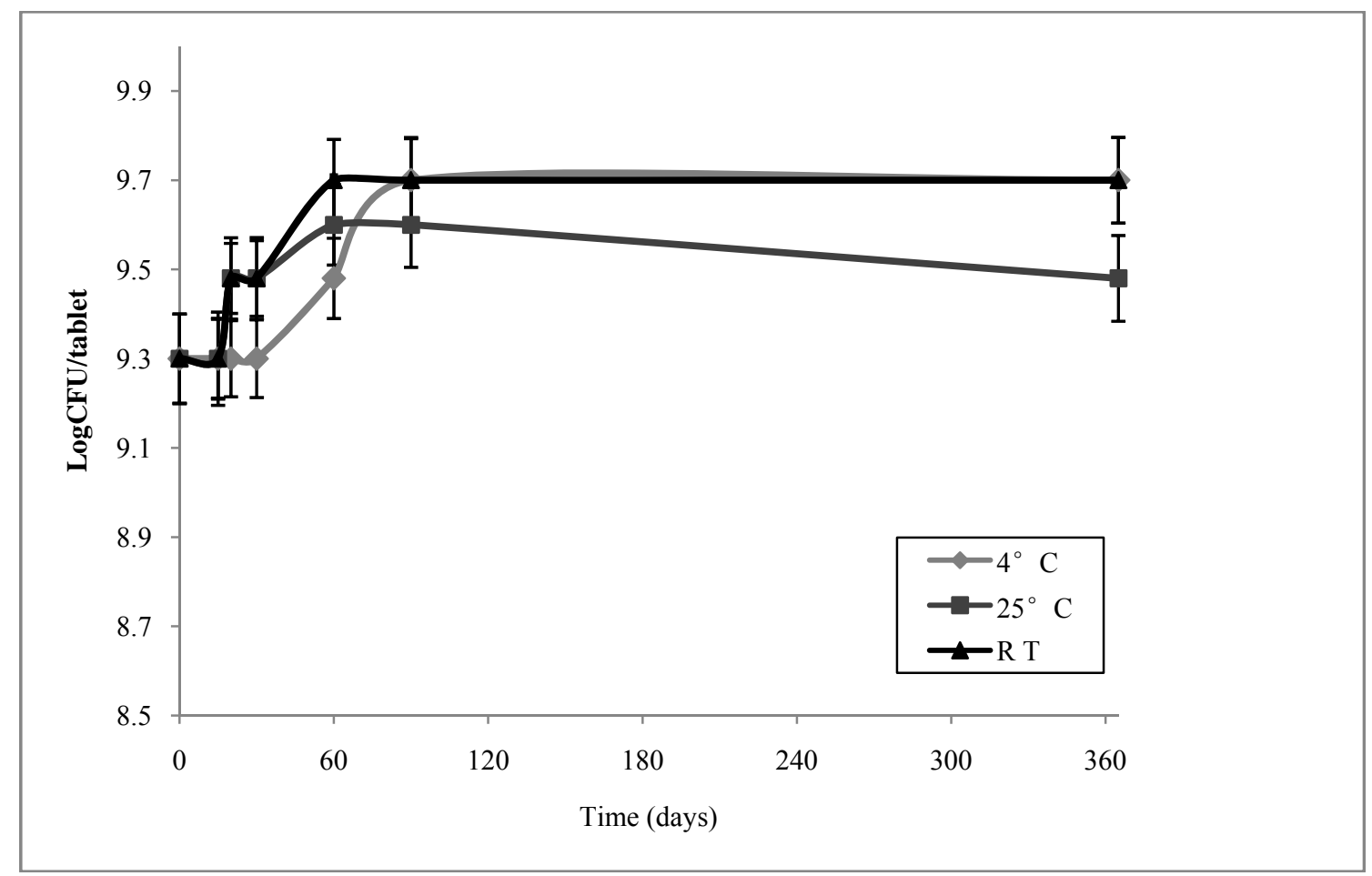

Fig. 6 Formulation 14 storage stability and bacteria survival $(\operatorname{logCFU} /$ tablet) during 365 days $(n=3)$ at different storage temperatures $\left(4^{\circ} \mathrm{C}, 25^{\circ} \mathrm{C}\right.$ and room temperature). 
Eudragit L-100 and Methocel ${ }^{\circledR}$ K-15 combination. As we have seen in Table 5, Eudragit L-100 has a great influence in probiotic protection, so Formulations 10 and 14 have the best acid resistance. However, Formulation 10 was refused because of its higher amount of sodium alginate since in a previous work we notify that $\mathrm{pH}$ of the medium may influence negatively the rheology of alginate gel [64], we can see this damage in Fig. 1. All in all, we studied the viability of Formulation 14 during 365 days; tablets were stored at different conditions of temperature (RT, $4{ }^{\circ} \mathrm{C}, 25^{\circ} \mathrm{C}$ ). In a previous reported work, we had a decrease in viability after 180 days [64], so the aim in this study was to enhance and improve the stability of our tablets.

As we can see in Table 6, the viability inside our tablets did not change throughout the study $\left(10^{9}\right.$ UFC/tablet) at the different temperatures. Owing to the results, we could confirm that the initial shock caused by the pressure had no effect on the remaining bacteria and did not make them more sensitive in storage conditions, thus the effect of both time and compression pressure on bacterial viability are independent [59]. Probiotics need to tolerate processing and storage conditions in order to be viable in a commercial product at the end of its shelf-life (> $\left.10^{6} \mathrm{CFU} / \mathrm{g}\right)$ [65].

\section{Conclusions}

Probiotics have a brilliant future; applications will be both in the food domain and in very specific disease situations, where they can play a truly therapeutic role. Success, however, will depend on a number of, mostly interlinked, conditions. The need arises to develop new formulations with them, which overcome problems associated with these microorganisms and assure their survival at the end of their shelf life in a suitable number of viable cells. Among the different matrix tablet formulations that were developed with Lactobacillus coryniformis CECT 5711, the combination of alginate sodium (25 mg), Methocel ${ }^{\circledR}$ K-15 M EP (100 mg) and Eudragit ${ }^{\circledR}$ L-100 (75 mg) had the best technological and viability assays results, as well as good biocompatibility and biodegradability polymers properties. The viability inside tablets after compression was $5 \times 10^{9} \mathrm{CFU} /$ tablet, so tablets offer an amazing protection to probiotic cells during this process. Furthermore, once tablets had passed stomach acid medium, the viability decreased in $1 \operatorname{logCFU}\left(5 \times 10^{8}\right.$ CFU/tablet) but it is already an effective dosage. Thus, this tablet dosage form is certainly an interesting way to improve probiotic resistance in harsh conditions and allows the strain to reach the therapeutic target in adequate amounts.

Stability study confirmed a tablet viability of $10^{9}$ during 365 days at different temperatures reaching our goals. If we consider all of these properties, the formulation proposed to Lactobacillus coryniformis CECT 5711 would be optimal for being marketed. While it is essential to refuse all false claims and prevent misleading information being distributed to the public, the possibility to communicate positively proven health benefits is necessary to promote the use of probiotics in a number of conditions that have the potential to reduce substantially the health care cost for society.

\section{References}

[1] Preidis, G. A., and Versalovic, J. 2009. "Targeting the Human Microbiome with Antibiotics, Probiotics and Prebiotics: Gastroenterology Enters the Metagenomics Era.” Gastroenterology 136: 2015-31.

[2] Champagne, C. P., Ross, R. P., Saarela, M., Hansen, K. F., and Charalampopoulos, D. 2011. "Recommendations for the Viability Assessment of Probiotics as Concentrated Cultures and in Food Matrices.” International Journal of Food Microbiology 149: 185-93.

[3] Sanders, M. E., Heimbach, J. T., Pot, B., Tancredi, D. J., Lenoir-Wijnkoop, I., Lahteenmaki-Uutela, A., et al. 2011. "Health Claims Substantiation for Probiotic and Prebiotic Products.” Gut microbes 2: 127-33.

[4] Dubey, A. P., Rajeshwari, K., Chakravarty, A., and Famularo, G. 2008. "Use of VSL\#3 in the Treatment of Rotavirus Diarrhea in Children: Preliminary Results.” Journal of Clinical Gastroenterology 42 (Suppl. 3 Pt. 1): 126-9.

[5] Elmer, G. W., and McFarland, L. V. 2001. 
"Biotherapeutic Agents in the Treatment of Infectious Diarrhea." Gastroenterology Clinics 30: 837-54.

[6] Hempel, S., Newberry, S. J., Maher, A. R., Wang, Z., Miles, J. N., and Shanman, R. 2012. "Probiotics for the Prevention and Treatment of Antibiotic-Associated Diarrhea: A Systematic Review and Meta-analysis." Journal of the American Medical Association 307: 1959-69.

[7] De Vrese, M., and Offick, B. 2010. Bioactive Foods in Promoting Health. Kiel: Institute of Physiology and Biochemistry of Nutrition, Federal Dairy Research Center, 205-27.

[8] Galvez, J., Comalada, M., and Xaus, J. 2010. "Prebiotics and Probiotics in Experimental Models of Rodent Colitis: Lessons in Treatment or Prevention of Inflammatory Bowel Diseases, Bioactive Foods in Promoting Health." In Probiotics and Prebiotics 35: 589-610.

[9] Meijer, B. J., and Dieleman, L. A. 2011. "Probiotics in the Treatment of Human Inflammatory Bowel Diseases." Journal of Clinical Gastroenterology 45: 139-44.

[10] Talaie, F., Atyabi, F., Azjdarzadeh, M., Dinarvand, R., and Saadatzadeh, A. 2013. "Overcoming Therapeutic Obstacles in Inflammatory Bowel Diseases: A Comprehensive Review on Novel Drug Delivery Strategies." European Journal of Pharmaceutical Science and Research 49: 712-22.

[11] Guslandi, M., Mezzi, G., Sorghi, M., and Testoni, P. A. 2000. "Saccharomyces boulardii in Maintenance Treatment of Crohn's Disease." Digestive Diseases and Sciences 45: 1462-4.

[12] Montalto, M., Curigliano, V., Santoro, L., Vastola, M., Cammarota, G., Manna, R., et al. 2006. "Management and Treatment of Lactose Malabsorption." World Journal of Gastroenterology 12: 187-91.

[13] Gotteland, M., Brunser, O., and Cruchet, S. 2006. "Systematic Review: Are Probiotics Useful in Controlling Gastric Colonization by Helicobacter pylori?.” Alimentary Pharmacology and Therapeutics 23: 1077-86.

[14] Francavilla, R., Lionetti, E., Castellaneta, E. P., Magista, A. M., Maurogiovanni, G., Bucci, N., et al. 2008. "Inhibition of Helicobacter Pylori Infection in Humans by Lactobacillus reuteri ATCC 55730 and Effect of Eradication Therapy: A Pilot Study." Helicobacter 13: 127-34.

[15] Patel, A., Shah, N., and Prajapati, J. B. 2013. "Clinical Appliance of Probiotics in the Treatment of Helicobacter Pylori Infection-A Brief Review." Zhurnal Mikrobiologii, Epidemiologii, i Immunobiologii XX: 1-9.

[16] Alexandre, Y., Le Blay, G., Boisramé-Gastrin, S., Le Gall, F., Héry-Arnaud, G., Gouriou S., et al. 2014. "Probiotics: A New Way to Fight Bacterial Pulmonary Infections? Les Probiotiques: Une Nouvelle Armethérapeutiquecontre Les
Infections Respiratoires?." Médecine et Maladies Infectieuses 44: 9-17.

[17] Larsen, L. A., Raben, A., Haulrik, N., Hansen, A. S., Manders, M., and Astrop, A. 2000. "Effect of 8 Week Intake of Probiotic Milk Products on Risk Factors for Cardiovascular Diseases.” European Journal of Clinical Nutrition 54: 288-97.

[18] Xiao, J. Z., Kondo, S., Takahashi, N., Miyaji, K., Oshida, K., Hiramatsu, S., et al. 2003. "Effects of Milk Products Fermented by Bifidobacterium longum on Blood Lipids in Ratsand Healthy Adult Male Volunteers." Journal of Dairy Science 86: 2452-61.

[19] Nguyen, T. D., Kang, J. H., and Lee, M. S. 2007. "Chacarterization of Lactobacillus plantarum $\mathrm{PH} 04$, a Potential Probiotic Bacterium with Cholesterol-Lowering Effects." International Journal of Food Microbiology 113: 358-61.

[20] Tulika, A., Satvinder, S., and Kumar Sharma, R. 2013. "Probiotics: Interaction with Gut Microbiome and Antiobesity Potential." Nutrition 29: 591-6.

[21] Qin, J., Li, Y., Cai, Z., Li, S., Zhu, J., Zhang, F. et al. 2012. "A Metagenome-Wide Association Study of Gut Microbiota in Type 2 Diabetes." Nature 490: 55-60.

[22] Ozdemir, O. 2010. "Various Effects of Different Probiotic Strains in Allergic Disorders: An Update from Laboratory and Clinical Data." Clinical and Experimental Immunology 160: 295-304.

[23] Waligora-Dupriet, A. J., and Butel, M. J. 2012. "Microbiota and Allergy: From Dysbiosis to Probiotics, Allergic Diseases-Highlights in the Clinic, Mechanisms and Treatment." Rijeka 21:413-34.

[24] Bunselmeyer, B., and Buddendick, K. 2010. "Probiotics and Prebiotics-Prevention and Therapy in Atopic Eczema." In Bioactive Foods in Promoting Health: Probiotics and Prebiotics 19: 279-92.

[25] Zhu, Y., Luo, M., Jobin, C., and Young, H. 2011. "Gut Microbiota and Probiotics in Colon Tumorigenesis." Cancer Letters 309: 119-27.

[26] Serban, D. E. 2013. "Gastrointestinal Cancers: Influence of Gut Microbiota, Probiotics and Prebiotics." Cancer letter 345: 258-70.

[27] Lannitti, T., and Palmieri, B. 2010. "Therapeutical Use of Probiotic Formulations in Clinical Practice." Clinical Nutrition 29: 701-25.

[28] Theodorakopoulou, M., Perros, E., Giamarellos-Bourboulis, E. J., and Dimopoulos, G. 2013. "Controversies in the Management of the Critically Ill: The Role of Probiotics." International Journal of Antimicrobial Agents 42: 41-4.

[29] Martín, R., Olivares, M., Marín, M. L., Xaus, J., Fernández, L., and Rodríguez, J. M. 2005. "Characterization of a Reuterin-Producing Lactobacillus 
coryniformis Strain Isolated from a Goat's milk Cheese." International Journal of Food Microbiology 104: 267-77.

[30] Lara-Villoslada, F., Sierra, S., Martín, R., Delgado, S., Rodríguez, J. M., Olivares, M., et al. 2007. "Safety Assessment of Two Probiotic Strains, Lactobacillus coryniformis CECT 5711 and Lactobacillus gasseri CECT 5714." Journal of Applied Microbiology 103: 175-84.

[31] Olivares, M., Díaz-Ropero, M. P., Gómez, N., Lara-Villoslada, F., Sierra, S., Maldonado, J. A., et al. 2006. "The Consumption of Two Probiotic Strains, Lactobacillus coryniformis CECT 5711 and Lactobacillus gasseri CECT 5714, Boost the Immune System of Healthy Humans.” International Microbiology 9: 47-52.

[32] Martínez-Cañavate, A., Sierra, S., Lara-Villoslada, F., Romero, J., Maldonado, J. A., Boza, J., et al. 2009. "A Probiotic Dairy Product Containing L. gasseri CECT 5714 and L. coryniformis CECT 5711 Induces Immunological Changes in Children Suffering from Allergy." Pediatric Allergy and Immunology 20: 592-600.

[33] Maggi, L., Mastromarino, P., Macchia, S., Brigidi, P., Pirovano, F., Matteuzzi, D., et al. 2000. "Technological and Biological Evaluation of Tablets Containing Different Strains of Lactobacilli for Vaginal Administration." European Journal of Pharmaceutics and biophaRmaceutics 50:389-95.

[34] Sanchez, M. T., Ruíz, M. A., and Morales, M. E. 2015. "Microorganismos Probióticos Salud." Ars Pharmaceutica 56: 45-59.

[35] Alderman, D. A. 1984. "A Review of Cellulose Ethers in Hydrophilic Matrices for Oral Controlled-Release Dosage Forms." International Journal of Pharmaceutical Technology \& Product Manufacturer 5: 175-9.

[36] Colombo, P., Bettini, R., and Peppas, N. A. 1999. "Observation of Swelling Process and Diffusion Front Position during Swelling in Hydroxypropyl Methyl Cellulose (HPMC) Matrices Containing a Soluble Drug." Journal of Controlled Release 61: 83-91.

[37] Siepmann, J., and Peppas, N. A. 2001. "Modelling of Drug Release from Delivery Systems Based on Hydroxypropyl Methylcellulose (HPMC)." Advanced Drug Delivery Review 48: 139-57.

[38] Vueba, M. L., Batista de Carvalho, L. A. E., Veiga, F., Sousa, J. J., and Pina, M. E. 2004. "Influence of Cellulose Ether Polymers on Ketoprofen Release from Hydrophilic Matrix Tablets." European Journal of Pharmaceutics and Biopharmaceutics 58: 51-9.

[39] Viridén, A., Wittgren, B., and Larsson, A. 2009. "Investigation of Critical Polymer Properties for Polymer Release and Swelling of HPMC Matrix Tablets." European Journal of Pharmaceutical Science 36: 297-309.

[40] Shukla, R. K., and Tiwari, A. 2012. "Carbohydrate
Polymers: Applications and Recent Advances in Delivering Drugs to the Colon." Carbohydrate Polymers 88: 399-416.

[41] Siepmann, J., and Peppas, N. A. 2012. "Modeling of Drug Release from Delivery Systems Based on Hydroxypropyl Methylcellulose (HPMC)." Advanced Drug Delivery Review 64: 163-74.

[42] Celine, L., Lai, C., Ai, C., and Paul, H. 2006. "Evaluation of Sodium Alginate as Drug Release Modifier in Matrix Tablets." International Journal of Pharmaceutics 309: 25-37.

[43] Sriamornsak, P., Thirawong, N., and Korkerd, K. 2007. "Swelling, Erosion and Release Behavior of Alginate-Based Matrix Tablets." European Journal of Pharmaceutics and Biopharmaceutics 66: 435-450.

[44] Ranga, K. V., and Padmalatha, D. K. 1988. "Swelling Controlled-Release Systems: Recent Developments and Applications." International Journal of Pharmaceutics 48: $1-13$.

[45] Colombo, P., Bettini, R., Santi, P., De Ascentiis, A., and Peppas, N. A. 1996. "Analysis of the Swelling and Release Mechanism from Drug Delivery Systems with Emphasis on Drug Solubility and Water Transport." Journal of Controlled Release 39: 231-7.

[46] Colombo, P., Bettini, R., Santi, P., and Peppas, N. A. 2000 "Swellable Matrices for Controlled Drug Delivery: Gel-Layer Behavior, Mechanisms and Optical Performance." Pharmaceutical Science \& Technology 3: 198-204.

[47] Ferrero, C., Massuelle, D., Jeannerat, D., and Doelker, E. 2008. "Towards Elucidation of the Drug Release Mechanism from Compressed Hydrophilic Matrices Made of Cellulose Ethers. I. Pulse-Field-Gradient Spin-Echo NMR Study of Sodium Salicylate Diffusivity in Swollen Hydrogels with Respect to Polymer Matrix Physical Structure." Journal of Controlled Release 128: 71-9.

[48] Maderuelo, C., Zarzuelo, A., and Lanao, J. M. 2011. "Critical Factors in the Release of Drugs from Sustained Release Hydrophilic Matrices." Journal of Controlled Release 154: 2-19.

[49] Zahirul, M., Khan, I., Prebeg, Z., and Kurjakovic, N. 1999. “A pH-Dependent Colon Targeted Oral Drug Delivery System Using Methacrylic Acid Copolymers. Manipulation of Drug Release Using Eudragit L 100-55 and Eudragit S100 Combinations." Journal of Controlled Release 58: 215-22.

[50] Rujivipat, S., and Bodmeier, R. 2010. "Improved Drug Delivery to the Lower Intestinal Tract with Tablets Compression-Coated with Enteric/Nonenteric Polymer Powder Blends." European Journal of Pharmaceutics and Biopharmaceutics 76: 486-92.

[51] Foligné, B., Daniel, C., and Pot, B. 2013. "Probiotics from 
Research to Market: The Possibilities Risk and Challenges.” Current Opinion of Microbiology 16: 284-92.

[52] Stadler, M., and Viernstein, H. 2003. "Optimization of a Formulation Containing Viable Lactic Acid Bacteria.” International Journal of Pharmaceutics 256: 117-22.

[53] Klayraung, S., Viernstein, H., and Okonogi, S. 2009. "Development of Tablets Containing Probiotics: Effects of Formulation and Processing Parameters on Bacterial Viability.” International Journal of Pharmaceutics 370: 54-60.

[54] Kotla, N. G., Gulati, M., Singh, S. K., and Shivapooja, A. 2014. "Facts, Fallacies and Future of Dissolution Testing of Polysaccharide Based Colon-Specific Drug Delivery.” Journal of Controlled Release 178: 55-62.

[55] Kiekens, F., Zelko, R., and Remon, J. P. 2000. "Effect of Storing Conditions on the Tensile Strength of Tablets in Relation to the Enthalpy Relaxation of the Blinder.” Pharmaceutical Research 17: 490-3.

[56] Plumpton, E. J., Gilbert, P., and Fell, J. T. 1986. "The Survival of Microorganisms during Tableting." International Journal of Pharmaceutics 30: 241-6.

[57] Gupta, V., and Garg, R. 2009. "Probiotics.” Indian Journal of Medical Microbiology 27: 2015-31.

[58] Huang, Y., and Adams, M. C. 2004. "In Vitro Assessment of the Upper Gastrointestinal Tolerance of Potential Probiotic Dairy Propionibacteria.” International Journal of Food Microbiology 91: 253-60.

[59] Muller, C., Mazel, V., Dausset, C., Busignies, V., Bornes, S., Nivoliez, A., et al. 2014. "Study of Lactobacillus rhamnosus Lcr35 Propertis after Compression and Proposition of a Model to Predict Tablet Stability.”
European Journal of Pharmaceutics and Biopharmaceutics 88: 787-94.

[60] Senaka- Ranadheera, C. S., Evans, C. A., Adams, M. C., and Baines, S. K. 2012. "In Vitro Analysis of Gastrointestinal Tolerance and Intestinal Cell Adhesion of Probiotics in Goat's Milk Ice Cream and Yogurt.” Food Research International 49: 619-25.

[61] Marteau, P., Pochart, P., Bouhnik, Y., and Rambaud, J. C. 1993. "Fate and Effects of Some Transiting Microorganisms in the Human Gastrointestinal Tract." World Review of Nutrition and Dietetics 74: 1-21.

[62] Marterau, P., and Shanahan, F. 2003. "Basic Aspects and Pharmacology of Probiotics: An Overview of Pharmacokinetics, Mechanisms of Action and Side-Effects.” Best Practice \& Research Clinical Gastroenterology 17: 725-40.

[63] Adams, C. A. 2010. "The Probiotic Paradox: Live and Dead Cells Are Biological Response Modifiers.” Nutrition Research Reviews 23: 37-46.

[64] Villena, M. J., Lara-Villoslada, F., Ruíz, M. A., and Morales, M. E. 2015. “Development of Gastro-Resistant tablets for the Protection and Intestinal Delivery of Lactobacillus fermentum CECT 5716.” International Journal of Pharmaceutics 487: 314-9.

[65] Chaikham, P., Apichartsrangkoon, A., Jirarattanarangsri, W., and Van de Wiele, T. 2012. "Influence of Encapsulated Probiotics Combined with Pressurized Longan Juice on Colon Microflora and Their Metabolic Activities on the Exposure to Simulated Dynamic Gastrointestinal Tract.” Food Research International 49: 133-42. 